\title{
Chapter 5 \\ Transformative Literacy as the Ability to Look Forward from Within
}

\author{
Nicole Dewandre
}

\begin{abstract}
Acquiring transformative literacies calls for a critical review of our underlying conceptual assumptions, in order to bring new light to old words, such as human, equality, freedom and power. Indeed, the transition towards sustainability requires leaving behind the modern paradigm, and embracing a conceptual framework proposed by Hannah Arendt, notably in the Human Condition. With her reconceptualisation of humanness, focused on relationality instead of rationality, she creates the conditions for cherishing and honouring interdependence, from each other, from artefacts and from nature. With this renewed understanding of what it means to be human and how it entails to rely on nature, Arendt offers a new framework that dissolves misleading beliefs and activates alternative ways to look and engage with reality in a meaningful way. And so she does, by keeping fear and rage away, but instead mobilising trust and ...love of the world, as difficult it may be.
\end{abstract}

Keywords Hannah Arendt · Relational self • Rational subject • Modernity • Sustainability $\cdot$ Human condition $\cdot$ Conceptual framing $\cdot$ Plurality $\cdot$ Natality

\subsection{Introduction}

In 2006, European Commissioner Potočnik, then in charge of research and innovation policy, created a new unit entitled "Sustainable Development" in the reorganisation that took place in DG Research and Innovation, to ensure that EU-funded research and innovation would fully support the renewed EU Sustainable Development Strategy. As Head of this "sustainable development unit", I experienced being trapped in a sort of dialogue of the deaf: on the one hand, those alerting on the dangers of climate change and the need to act before it is too late; on the other hand, those denying climate change or considering that the future or the invisible hand will be good enough to tackle this challenge. I was struck by the inadequacy of this infernal dilemma. They were too perfect enemies to avoid a suspicion of being just

\footnotetext{
N. Dewandre $(\bowtie)$

European Commission, 115, avenue Jupiter, 1190 Brussels, Belgium

e-mail: nicole.dewandre@ec.europa.eu
} 
two sides of the same coins. I started wondering (Dewandre, 2011): "Can we stand between catastrophism and denial?" as indeed this seemed to me the condition for paving the way and stepping in the transformation towards sustainability. If there is obvious consensus, especially for this readership, on the fact that denial is wrong and irresponsible, the reasons for which catastrophism is not a better option deserve further explanation. In that contribution, I aimed at unveiling why catastrophism undermines the conditions in which transformative literacy could strive. It comes down to the fact that mobilising fear to reach an objective, may work at personal level -for some of us- and for a restricted kind of objectives! However, it does not deliver politically, if what is required is joint mobilisation for something and not running away or protecting ourselves from something. The transformation that is called for to ensure a sustainable future for humankind on earth cannot be achieved with the mind-set and the tools required to strike a war or to go to the moon! Yes, indeed, we came to the point where staying on earth proves to be much more challenging for humankind-and hence for politics - than exploring the universe.

In this paper, I'll suggest that the challenge of developing transformative literacies can best be tackled if we acknowledge the need to let go of some fundamental features of modernity, that have been very fertile for some centuries, but are now highly limiting and hindering the development of these transformation literacies. These modern features have shaped the human grip on the world, but now, it obstructs the way towards solutions, and has to be "removed" from our minds, so to speak. These modern features draw from the excessive reliance on rationality and on causality, together with the illusion of omnipotence that faith in progress nurtures as a potential realistic goal. It is my assumption that those became ineffective and stopped providing a grip on reality. As a result, sticking to these modern features undermine the meaningfulness of policies and political action, and eventually, threatens democratic regimes altogether. In the first section, I shall outline what these modern features are. In a second section, I shall outline why, in my view, Hannah Arendt provides an appropriate alternative to the modern conceptual matrix, that we should embrace to boost our ability to develop transformative literacies. Arendt reconceptualises the human condition, overwriting the modern definition of Man as a rational subject. She forges a concept of humanness that completes, as it were, the modern rationality with two other characteristics of humanness: our animality or organic nature, on the one hand, and our plurality, i.e., that "men, not Man, live on earth and inhabit the world" (Arendt, 1998: 7), on the other hand. In the third and last section, I shall highlight the way in which this Arendt's framework enables transformative literacies.

\subsection{The Deceptive Structural Features of Modern Times}

Based both on my long experience as a European Commission's civil servant and occupying a persistent reflexive stance, I am struck by the critical importance of implicit framing and assumptions in the practice of policy-making. These implicit 
framing and assumptions determine what kind of reasoning and what kind of evidence are considered sound or not, what is presumed as shared wisdom-sometimes even truth-what can determine legitimate trade-offs or raise legitimate objections, what seems to be unquestionable, etc.... It conditions what makes sense and what gets traction in policy debates. The importance of implicit framings is not restricted to policymakers, as such, but conditions the whole policymaking ecosystem (lobbyists, stakeholders, media, etc....). I came to the opinion that policy-making was somehow stuck in modernity, while reality and the challenges it brings to policy-making in the twenty-first century cannot be addressed effectively anymore with modern implicit assumptions (Dewandre, 2018). Let us characterise the modern implicit framing and assumptions alongside two concepts: what relations are about and what agents are about? After all, a system is a combination of agents relating to each other. And a political system is a combination of political agents relating to each other in an ever-changing environment in which these relations take place. Hence, let us zoom in on what we consider a relation, and what we consider an agent.

\subsubsection{Relations Either Vertical or Agonistic}

The conceptualisation of relations per se in modernity is rooted in causality. Understanding a relation is taken to be identifying a cause that shall necessarily lead to the effect. In social sciences, too often mimicking Newtonian mechanics, this takes the form of who is on top of the other and who determines the outcome for the other. The top is deemed to determine the bottom, as simply that we all visualise where a stone dropped from above will end up, i.e., at the bottom. The pervasiveness of the bottom-up/top-down metaphor in policymaking circles unveils this implicit verticality of what elucidating a relation entails, and reveal that relations, when coined with a modern mind-set, are considered as linking together two poles, in an asymmetric manner: one pole is active and has power, and the other pole is passive, dominated or victim. When there is no causal relation between two entities, then they are deemed to be independent, in order to reach a balance or equilibrium. This again draws on the Newtonian metaphor, that of considering agent's interaction as an interaction among forces which must neutralise each other, in order to ensure stability. This shows how strongly modernity is rooted in a resentment-not to say a denial - of dependence. Indeed, independence is at its best, when it takes the form of a "rapport de force". When several actors agree together, then there is a suspicion of bias. One of them is characterised as the leader, the only one that counts (active pole), and others are mere followers (passive pole). 


\subsubsection{Agents as Rational Subjects}

In modern terms, the archetypical figure of an agent is that of a rational subject. Indeed, the modern definition of humanness puts rationality at its core. Far from the philosophical approach to reason, in everyday life, reason has been downgraded to narrowly understood and selfish interest, so that in policymaking agents are identified to their interests. It is commonly considered that "being rational" became synonymous to "being interest-led" or to be a "stakeholder." The word "subject", and its derivative "subjectivity", pairs naturally with "object" and "objectivity". Interestingly, subject, in its grammatical meaning, is on top of the object, but in its medieval meaning, it is under the king or the lord. Hence, "subject," as a concept, has a dual form: in its upper version, the rational subject is someone on top of the situation, while, in its lower version, the rational subject is someone under control, whose rationality expresses itself through its compliance with expectations or instructions from others, like the subject in front of the king. Hence, the concept of rational subject to characterise agents fits perfectly with the vertical or agonistic conceptualisation of relations.

\subsection{Arendt's Alternative Conceptual Matrix}

When I encountered Arendt's work in the first decade of this century, I was illuminated by its relevance and it helped me making sense of my own administrative experience. By reading Arendt each morning before going to work, I could reconcile thinking with what I was doing. It took quite a long time - a decade - to understand how and why. Now, I can spell it out in these simple terms: Arendt made me understand that the atrocities of the Shoah was a form of logic ending of pushing the modern assumptions to their ultimate consequences. And, more importantly, Arendt does not stop there but provides an original alternative conceptual approach, notably by redefining humanness and politics. Indeed, modern assumptions characterise not only what knowledge is supposed to be (laws that can predict an effect, once a cause is identified), but also what policy-making should be. At its best, policy actions should be the causes (means) that deliver intended effects (objectives). For decades, policymakers have been aware that it is not so simple and never fully worked like that. They are aware of "unintended effects" or acknowledge disappointment about outcomes. But this is often attributed to an increasing complexity, and the need to overcome it, either with more knowledge, tools or power. In the meantime, in the academia, post-modern scholars have highlighted the shortcomings of modern determinism, but they seem to stay stuck in the deconstruction of modern referential frameworks, without proposing an alternative. Hence, Arendt's unique relevance to this era is that beyond her critique of Modernity, she provides an alternative framing to the implicit and overdue Modern framing. And she lays the ground for that alternative in The Human Condition (Arendt, 1998), through an analysis of what 
it means for human beings to be active, and her proposal to distinguish three types of activity: labour, work and action. By the way, a lot of Arendt's work is about clarifying distinctions, be they binary (e.g., thought/knowledge or necessity/freedom) or ternary (e.g., labour/work/action or thinking/willing/judging). When she does so, it is never in an either-or fashion, but always in an inclusive both ${ }^{1}$-and manner, putting value and meaning in each of the terms of the distinction. With that, she offers a framework that allows three dimensions. This is still clear enough to provide a grip and overcome the cost of an excessive reductionism to one-only dimension. One last remark before outlining the alternative framework proposed by Arendt. Her framework is valid, but it does not pretend to be the single valid one. With her heuristic approach, she teases the consent of her reader, instead of providing a demonstration that forces adhesion of the mind. And, from my standpoint, her proposal is the clearest I have encountered so far.

\subsubsection{Agents as Relational Selves}

By acknowledging that labour is the activity that stems from the fact that human beings are organic and have to survive, Arendt brings back biology at the core of humanness. Humans are biological beings! This was erased in the modern definition of humanness, as rationality was precisely what was supposed to distinguish humans from nature. By recalling this evidence that we are biological beings, Arendt provides a renewed restricted understanding of what necessity is about. For Arendt, necessity is and should remain understood in a very strict way, which is the "burden of biological life, weighing down and consuming the specifically human life-span between birth and death" (Arendt, 1998: 119). Our biological condition "bind[s] all of us in pain and necessity" (Arendt, 1998: 119): this is a matter of fact. "This darkness is natural" (Arendt, 1998: 119). "The price for elimination of life's burden from the shoulders of all citizens ... by no means consisted only in the violent injustice of forcing one part of humanity into the darkness of pain and necessity" (Arendt, 1998: 119). I read this as plain common sense from a sound woman knocking on men's minds asking them: how did you come to forget that the life process is indeed indexed on pain and necessity? And it is precisely because of this harshness of life processes that human beings have strived to build shelters for their existence. This leads to a second characteristic humanness, i.e., its worldliness or the unnaturalness of human existence. Indeed, the fabrication of objects aims at providing some comfort for human existence. This second feature of the human condition, its unnaturalness, refers to the ability of human beings to make things according to a plan that they had in mind, or to their knowledge. The worldliness is not opposed to the biological dimension, but instead complementary to it. Last but not least, human beings are plural. Plurality entails (i) being equal to others belonging to the same plurality, (ii) being unique and (iii) with a who-identity, i.e., an identity revealing itself through

\footnotetext{
${ }^{1}$ Both is binary. It would be handy to have a similar word for a ternary distinction.
} 
speech and action with other beings from the same plurality. Plural beings are not equal in modern terms, i.e., from an objective and absolute point of view, but they are equal in relative and performative ways. They are relatively equal, insofar as they share common characteristics; they are performatively equal, as when acting together with other plural beings they grant each other equal status. The second element of plurality is uniqueness. As humans, our who, not our what, matters. And this who is unique. So, one of the things all humans have in common is that they are unique. Equality and uniqueness, far from being at odds with each other-as they are for modern-wired minds-are in Arendt's terms deeply coherent. Plurality is the concept which dissolves the modern omniscience-omnipotence utopia and which enables embracing diversity meaningfully.

With these three features of The Human Condition (Arendt, 1998), i.e., life, worldliness and plurality, Hannah Arendt highlights the inherently relational nature of humanness. Instead of considering rationality as the overarching characteristics of humanness, with Arendt, we are invited to put relationality at the core of humanness. With relationality at the core of humanness, we keep in mind what we should never have forgotten: that human beings depend (i) on their environment to stay alive, (ii) on their artefacts for decent living conditions and (iii) on their plural peers to act in concert and reveal their own identity. It is all about embracing our relationality, without fear, conscious of our shared strengths and vulnerabilities. Arendt's reconceptualisation of humanness, around biology, worldliness and plurality is well reflected in the expression "relational self". In contradistinction with the word "subject", the word "self" encapsulates the fact that plural beings are not looking at each other vertically "from above" or "from below"—as rational subjects do to each other-but horizontally, from their own embodiment, at their own height.

\subsubsection{Relations Embracing Emergence, Adaptation and Cooperation}

In The Human Condition (Arendt, 1998), Arendt downplays her reconceptualisation of humanness by presenting it only as a step towards characterising what it means for human beings to be active. She writes in her introduction: "what I propose, therefore, is very simple: it is nothing more than to think what we are doing." (Arendt, 1998: 5) But, with the ternary distinction between labour, work and action, as fundamental distinct types of activities, Hannah Arendt paves also a way for upgrading the 1-D modern approach to relations into a 3-D one. Besides relations leading to predictable outcomes (verticality) or to mutual neutralisation (agonistic), this 3-D approach makes room-conceptually-for relations whose purpose is the revelation of identities of plural agents acting together, and for relations where political agents need to adapt to their environment instead of being on top of it. Being active entails a relation between a self, i.e., the person being active, and an other, that with which the self is engaging through the very fact of being active. If Arendt insists on the 
different types of self that are mobilised in each of the three types of activity: animal laborans for labour, homo faber for work and wo/man ${ }^{2}$ for action. I suggest shifting the focus to the different types of other that this ternary distinction entails. For the work activity, the other in the relation is an object. Indeed, for Arendt, work accounts for the activity of a single human being who mobilises means to reach her or his own objective. What is at stake in this mode of relation is control. This type of relation corresponds to the modern vertical mode of relation. But instead, of considering all relations on that hegemonic mode, Arendt brings two additional dimensions that allows to better conceptualise and understand relations.

For the action activity, the other in the relation is another self, a plural peer. As a type of human activity, action is rooted in plurality. What is at stake in this mode of relation is mutual respect and acting in concert. "In acting and speaking, men ... reveal ... their unique personal identities... This disclosure of 'who' in contradistinction of 'what' somebody is ... can almost never be achieved as a wilful purpose" (Arendt, 1998: 159). Hence, plurality is intimately connected with revealing our who-identities. Whereas the modern conceptual framework envisions relations among equals only as agonistic, Arendt's plurality is the very concept opening up to constructive and cooperative horizontal relations.

For the labour activity, the other in the relation is the milieu, understood as the part of the world surrounding the self, at a given moment, in a given circumstance. The life of human beings takes place within a milieu, which is a mix of nature and artefacts that surrounds them and sustains their life. What is at stake in the relation between a self and an other-as-a-milieu is survival, orientation, exploration and adaptation.

In The Human Condition, beyond distinguishing labour, work and action, Hannah Arendt suggests a hierarchy among them: labour is at the bottom and action is on the top. I agree with those arguing that this hierarchy is highly contestable (Pitkin, 1998), but maintain that the ternary distinction is illuminating and highly relevant, provided we consider its three dimensions as equally relevant for qualifying the human experience.

\subsection{Why Arendt's Conceptual Matrix can Boost Transformative Literacies}

\subsubsection{Shifting Underlying Implicit Assumptions have Concrete Consequences}

We are so used to consider soundness and objectivity as one and the same thing, that it is often considered that change of reality can only occur in the future, as a

\footnotetext{
${ }^{2}$ In her book, and in her work in general, Arendt did not engage in feminist thinking, and this has triggered legitimate and interesting debates in feminist scholarship. See notably Bonnie Honig "Feminist interpretations of Hannah Arendt". In this contribution, we consider that where and when Arendt speak of "man" or "homo", this includes woman as well.
} 
result of policy decisions or changes of strategies and behaviour. With that, we overlook the fact that judgments we make and decisions we take depend crucially on the conceptual grid - often revealed by metaphors-we live by (Lakoff \& Johnson, 2003). It is my view that the practical and performative mobilisation of Hannah Arendt's conceptual resources can achieve in the political realm, mutatis mutandis, what paradigmatic shifts achieve in the scientific realm. Embracing Arendt's conceptual framework will not change the reality itself in a teleological manner, but it can change radically the conditions in which transformative policies can be shaped and supported. Indeed, instead of fuelling frustration and dissatisfaction, it enables reconnecting with feasibility and meaning.

\subsubsection{New Standpoint: From Within and Among Peers}

Arendt's model provides a conceptual grounding for relations where something else other than control is at stake. And it does so in two ways:

- With the horizontal mode of relations which accounts for relations with other plural beings, and is relying on trust and pervaded by mutual recognition. This offers a conceptual background for the "art of associating together" (Lloyd, 1995: 31), which is so critical for nonhegemonic politics.

- With the surrounding mode of relations, which accounts for relations with the other-as-milieu, and is pervaded by survival, orientation, exploration and adaptation. This offers a conceptual background for the need of policies to adapt to the environment and actualise the relevance of regulatory frameworks and policy initiatives, against continuous change.

This new standpoint, combining control together with the non-dramatic impredictability of acting in concert, on the one hand, and with adaptation or coping with, on the other hand, offers new perspectives. It leads to loading words, such as identity, freedom and power with a new meaning, so that what used to be seen as sound and meaningful appears now as stupid or meaningless, while what looked as out of reach now seems a sound approach to be embraced. Indeed, meaning conditions judgments, and ultimately decisions, based on them.

\subsubsection{New Meaning of Identity, Freedom and Power}

\section{On identity}

In modern terms, identity is a stable and intimate attribute that each of us - as rational subject - is entitled to own, choose and control. The dynamic dimension of social identities is understood in a deterministic way, in the form of a fabrication or a production process. It is a what-identity, often reduced to attributes (wealth, profession, class, race, gender, sexual orientation) and their associated and differentiated 
loads of prestige. In her reconceptualisation of humanness, Arendt puts forward the revelatory nature of human identities. With that, she recalls that we do not control our identities, in the sense that we depend from others to access our own identities. With that essential distinction between what-identities (that apply to objects and things) and who-identities (that apply to peers), she provides a political grounding for something that is acknowledged in psychology, but overlooked in politics, i.e., our inherent interdependence, not only for mere survival but also for revealing and knowing who we are.

\section{On freedom}

In modern terms, freedom is assimilated to autonomy. As made clear in the French expression "Ma liberté s'arrête là où commence celle des autres", 3 for modern subjects, others are perceived as a hindrance to a greater freedom. Relations with others can only be ties, and others obstacles, unless and until they are turned into means. So, in a nutshell, for a rational subject, being free is being alone or in control. For Arendt, there cannot be freedom in deprivation or survival mode. Freedom can only be experienced once vital needs are ensured. Then, above that satiety threshold, freedom is experienced in public appearance through acting with peers, and thereby revealing our identities through speech and action. If toxic and adverse relations indeed hinder freedom, absence of relations is not a best alternative. Freedom stems from a rewarding and respectful interaction with peers. This is a relational approach to freedom. In a nutshell, instead of being considered as absence of constraints, independence or autonomy, Arendt's freedom is rooted in two conditions: (i) being beyond a satiety threshold and (ii) interacting with peers.

\section{On power}

In modern terms, power is considered as a Newtonian force, as a power over others. The richest is the most powerful, as if infinite wealth (or knowledge) could provide omnipotence. The bigger is most powerful, as infinite size could provide omnipotence. For Arendt, power stems from acting in concert. Power disappears when violence steps in. And domination is not power. As well put by Patricia Owens, for Arendt, "power springs up between people as they act together; it belongs to the group and disappears when the group disperses. It is a collective capacity. Until this coming together, it is only a potential" (Owens, 2008: 110).

Interestingly, Arendt never considers words, simply as description of action, but action per se. Yet, she acknowledges that the choice of words matter: "Power is actualized only where word and deed have not parted company, where words are not empty and deeds not brutal, where words are not used to veil intentions but to disclose realities, and deeds are not used to violate and destroy but to establish relations and create new realities." (Arendt, 1998: 200) With this very intense sentence, she spells out the conditions leading to a dissolution of power, i.e., when words are empty or veil

\footnotetext{
${ }^{3}$ In English...My freedom stops where that of others begins.
} 
intentions and deeds are brutal. ${ }^{4}$ And she affirms that power comes from establishing new relations and thereby creating new realities.

\subsubsection{Amor Mundi: Daring Confidence and Trust in Plurality and Natality ${ }^{5}$}

It is now time to spell out how the reconceptualisation of humanness proposed by Arendt paves the way beyond catastrophism and enables transformative literacies. Essentially, it is by acknowledging and facing with lucidity and courage that there is no other last resort than the sense of humanness we share with all human beings. Precisely, because there is no other last resort, it is by optimising humanness with relationality at its core, instead of denying it, that humankind shall develop transformative literacies. As flagged by Arendt, this requires taking some distance with the tradition of moral philosophy. "According to our tradition, all human wickedness is accounted for either by human blindness and ignorance or human weakness, the inclination to yield to temptation" (Arendt, 2003: 79). Indeed, catastrophists point to the lack of awareness or lack of will, as if awareness or will were enough to redress the situation and avoid climate change. How could guilt and fear unleash transformative power? Transformation can best take place when it relies on the "simple fact that people are at least often tempted to do good and need an effort to do evil" (Arendt, 2003: 80). If this was not the case, human beings would since long have disappeared from the earth, through a massive self-destruction. Instead of that, the human species is still there, and indeed, the challenges it is faced with, and most importantly climate change challenge, is the outcome of modern developments, modern science and modern moral assumptions. The new momentum that Arendt provides with her relational reconceptualisation of humanness combines two dynamics: a negative one and a positive one. On the negative side, it disables what is toxic in the modern legacy. On the positive side, it offers a new conceptualisation that reconnects reality and meaning, and provides a better grip on the challenges to be tackled.

To make room for transformative literacies requires disabling the modern underlying assumptions that it is by violating nature's secrets and exploiting it, that human knowledge can thrive and humankind progress. That does not mean that we have to consider nature as sacred and untouchable, which would be the other side of the same coin. But instead, with Arendt's reconceptualisation, always keep in mind that our lives depend from nature, and not from our control of it. Another modern assumption we need to let go is our expectations from "big others", as if "they" were powerful and "we" were powerless, or, in other words, as if the future depended on someone to be powerful enough and do good. This modern asymmetric approach to power where

\footnotetext{
${ }^{4}$ Indeed, Arendt has a very specific approach to power and violence; Instead of violence being the manifestation of power, in Arendt's view, power ends where violence begins.

5 In Arendt's work, natality is not what it is for demographers, i.e. birth rate in a given population. It refers instead to the fact that human beings are born beings, that they come to the world by birth.
} 
some look up at others who look down at them cannot deliver on transformative literacies. Transformative literacies cannot grow on the modern moral assumptions that guilt and fear are what hold each of us into account, and that if only we could, we would all engage in wickedness and laziness. Indeed, this conceptualisation of power as an attribute or a capacity of some human beings goes together with identifying power to a force, enabling someone to reach an objective. This understanding of power, as a mere instrument, crowds out the sense of purpose that acting in concert provides. Furthermore, it weights towards paying more attention to bad outcomes: indeed, it takes only one to declare a war, but it takes at least two to make peace. Beyond this extreme example of war and peace, all positive outcomes stem from acting in concert, and not from a superman or superwoman acting alone and saving the world, be it in the economic, political or social realms.

On the positive side, Arendt's reconceptualisation of humanness foregrounds what all human beings have in common. Plurality is not the same as the modern passion for equality. Paradoxically, this modern passion for equality led to paying attention to differences only, and spending a lot of energy, either combatting them or justifying them! Transformative literacies can grow out of foregrounding forcefully what human beings have in common, to start with. We all depend on resources and the world around us to survive and thrive. We all depend from others to experience freedom and access our own identity. All human beings resent being humiliated and cannot thrive without being respected by others. What we have in common takes different forms: we are all speaking beings, but we speak different languages. We all appreciate reciprocity and marks of respect, but these cultural habits differ across cultures. Hence, building on these shared characteristics, knowing they are at the root of diversification, creates the condition for acting in concert at all levels: with family and friends, at work with colleagues, in politics, be it at local, regional, national or global levels.

The power that stems from plurality has nothing to do with competition or race. These are only games. Instead, it stems from the shared consciousness of making meaningful and appropriate decisions, in accord with our own responsibilities. Leading by example is what nurtures transformative literacies, as it resonates with one's own purpose and identity. Currently, millions of citizens lead by example when they change their behaviours, and engage in sustainable practices. Policymakers lead by example when they adopt policies that bring the structural support needed for citizens to live meaningfully. Stakeholders lead by example when they contribute proactively to transformative policies, instead of defending their narrowly expressed interests. By foregrounding the relational nature of humanness, Arendt invites us to cherish what we have in common instead of being afraid of each other or consumed, as it were, by the fears nurtured by our own (inner) ghosts. Arendt flags that political action is best when anchored in the love of the world, through embracing plurality and natality (Dewandre, 2015). She calls for reclaiming thaumadzein, the Greek wonder that has been overtaken by the modern doubt and suspicion. Indeed, another feature of modern epistemology is to associate trust with blindness and sometimes lack of intelligence, while doubt and suspicion would express intelligence and lead to robust knowledge. Similarly, in modern terms, knowledge and power are intimately 
connected. Being able to predict is a form of knowledge and, indeed, provides a grip to the knower. But what happens when what is predicted is to be avoided? The scientific predictions, or instead projections, make clear that we have to change course, to bend trajectories and to undergo transformations, if we are to keep climate change in acceptable limits and avoid trespassing planetary boundaries in such a way that the human species would be endangered. But scientific knowledge is silent on how to do that. This is where the art of politics comes in, and where meaning trumps truth to ensure adhesion and effectiveness.

Politics and predictability are like water and fire. Arendt insists upon the fact that action, the most political among the three types of activity, leads to unpredictable outcomes. This unpredictability is not an epistemic failure to be overcome. It is instead "the very texture of reality" (Arendt, 1998: 300) and the very condition for human freedom, as freedom is anchored in the human's ability to begin. As we, human beings, came to the world by birth, this constitutes us, human beings, as born beings, and thereby beginners. By insisting on the importance of natality for the political, Arendt anchors the political firmly both in the present and in an open-ended future. Unpredictability is an essential feature of this open-endedness. ${ }^{6}$ Unpredictability is to be accepted, together with harnessing knowledge. Indeed, knowledge is highly needed, but outcomes of action have to be embraced and become the new baseline, as there is no $\mathrm{Ctrl} Z$ function on reality, and multiple ways to look at it. The modern verticality, associated with the gravitational-inspired false common sense that the top dominates the bottom, made us somehow continue to live by the belief that life falls from heaven, in denial of the evidence that life comes from the ground (for the vegetal) or from the bodies (for animals, including humans). On earth and in the world, the bottom supports the top, not the other way around. Arendt's reconceptualisation allows dissolving misleading beliefs and representations, and activates alternative ways to look and engage with reality. The acknowledgment of a satiety threshold is essential in that pivotal move. Arendt disqualifies the modern "More is better" that is so misleading today. She writes: "abundance and endless consumption are [...] the mirage in the desert of misery... affluence and wretchedness are only two sides of the same coin; the bonds of necessity need not be of iron, they can be made of silk" (Arendt, 1990: 139). With Arendt, we can instead embrace "Enough is enough". This does not mean an authoritarian and objective decision by an external judge of what is enough for whom or of who has enough and who does not. This would indeed lead to an infernal surveillance society. "Enough is enough" can replace "More is better" in the following way. In a given context, "Enough is enough" provides an unambiguous compass to prioritise the needs of those below satiety over the needs of those above satiety. It does not condemn those above satiety, far from it, but it makes clear that in the public space those above satiety are there to contribute and cooperate, while policy-making should prioritise the needs of those below satiety, together with ensuring long-term sustainability. "Enough is enough" sheds light on the absence of legitimacy and meaningfulness of some requests from stakeholders when they

\footnotetext{
${ }^{6}$ This has nothing to do with any kind of praise for obscurantism. It does not fall in scope of this contribution to unfold this.
} 
threaten policymakers with adverse consequences, should their needs not be taken into account. Leaving "more is better" behind to embrace "Enough is enough" frees a huge potential of energy that can be fully dedicated to lift poverty, foster cohesion and ensure sustainability.

\subsection{Conclusion: Meaning as a Compass of Transformative Literacies}

With her rigorous conceptualisation, Hannah Arendt provides a stable ground for reconnecting EU-policy-making with the concerns and expectations of Europeans. The time is ripe. We have exhausted all the benefits of political modernity and the casualties of its reductionisms weaken and even threaten the stability of the European political ecosystem, in general and of the EU, in particular. Now is the time where we need to reconsider what is meaningful and what is not. On top of being dangerous and lead to inequalities, the endless exploitation of resources is - to start withmeaningless, and thereby hurting our own minds as much as the planet. Those in denial pay also a price for this denial. Let's ensure each of us is confronted with the shortcomings and the meaninglessness of modern assumptions. This new lens will disable a lot of claims and so-called interests. This shall create the conditions enabling human beings to acknowledge their shared strengths and vulnerabilities, their fundamental interdependence. We might be at one of those "rare moments when the chips are down" (Arendt, 1971: 446) and when the conditions are met to recognise Arendt as the conceptual mother of this "new and yet unknown age" (Arendt, 1998: 6) whose emergence we are witnessing and whose name will crystallize only in a few decades or centuries.

Acknowledgements This contribution would not have been possible without the strong encouragement of Petra Kuenkel, and for her active reading and commenting of earlier versions of the draft.

\section{References}

Arendt, H. (1990). On revolution. Penguin Books.

Arendt, H. (1998). The human condition (2nd ed.). University of Chicago Press.

Arendt, H. (2003). Responsibility and judgment. Schocken Books.

Dewandre, N. (2011). The sustainability concept: Can we stand between catastrophism and denial.

In C. Jaeger et al. (Eds.), European research for sustainable development (vol. 1). Springer. Accessed Feb 9, 2021, from https://link.springer.com/chapter/10.1007/978-3-642-19202-9_4.

Dewandre, N. (2015). Rethinking the human condition in a hyperconnected era: Why freedom is not about sovereignty but about beginnings. In L. Floridi (Eds.), The onlife manifesto (pp. 195215). Springer International Publishing. Accessed Aug 9, 2017, from https://link.springer.com/ 10.1007/978-3-319-04093-6_20. 
Dewandre, N. (2018). Political agents as relational selves: Rethinking EU politics and policy-making with Hannah Arendt. Philosophy Today 62(2).

Lakoff, G., \& Johnson, M. (2003). Metaphors we live by. University of Chicago Press.

Owens, P. (2008). The ethic of reality in Hannah Arendt. In D. Bell (Ed.), Political thought and international relations: Variations on a realist theme (pp. 105-121). Oxford University Press.

Pitkin, H. F. (1998). The attack of the blob: Hannah Arendt's concept of the social. The University of Chicago Press.

Open Access This chapter is licensed under the terms of the Creative Commons Attribution 4.0 International License (http://creativecommons.org/licenses/by/4.0/), which permits use, sharing, adaptation, distribution and reproduction in any medium or format, as long as you give appropriate credit to the original author(s) and the source, provide a link to the Creative Commons license and indicate if changes were made.

The images or other third party material in this chapter are included in the chapter's Creative Commons license, unless indicated otherwise in a credit line to the material. If material is not included in the chapter's Creative Commons license and your intended use is not permitted by statutory regulation or exceeds the permitted use, you will need to obtain permission directly from the copyright holder. 